\title{
Competition and Cooperation Relationships of Multi-category Ports Based on the Improved L-V Model
}

\author{
Zhiyi Lei ${ }^{1, *}$, Yifan Zhu ${ }^{1}$, and Liling Chen ${ }^{1}$ \\ ${ }^{1}$ College of Harbour, Coastal and Offshore Engineering, Hohai University, China
}

\begin{abstract}
The improved Lotka-Volterra model for the multi-goods of the multi-ports is proposed based on the competition of kinds of ecological populations in nature. Based on the analysis of the current throughput, annual average growth rate, potential throughput growth space, and the impacts of other port cargo throughput, the model establishes a competition coefficient matrix to determine the competitive cooperation model between different ports. The model is used to analyze the competition and cooperation relationship of different cargo types in four ports of Fujian. The results show that the model can reflect the mutual influence mechanism of competition and collaboration of multiple types of cargo in multiple ports, which can provide an effective and targeted basis for optimizing the cargo structure of ports and improving the competitive relationship of the ports.
\end{abstract}

\section{Background}

The Lotka-Volterra model was first proposed by the American ecologist Lotka[1] and the Italian mathematician Volterra[2] based on the Logistic model, and it was an important model to study ecological population relations, and was widely used in the fields of population, economy and chemistry. The model studied the interaction of different variables under the same environmental capacity and can intuitively reflect the relationship between different variables. Vladimir Balaz[3] used this model to analyze the dynamics of the coopetition evolution of telephony between the Czech Republic and the Slovak Republic during the period from 1948 to 2009. Nowadays, the model has been applied to many fields, including economy, transportation and port business[4-11].

In the area of port, the two-population model is mostly used, and the Lotka-Volterra model has not yet been fully developed. In reality, there are more than two ports in the same area in general. Due to the proximity of geographical location and limited market resources, the cargo structure of the ports are similar, the port functions are the same. The modes of cooperation among ports are not uniform, and it is necessary to comprehensively analyze the competing modes of the multiple types of cargo of multiple ports in order to determine the dominant cargo type of each port. This paper attempts to use the Lotka-Volterra model to qualitatively and quantitatively analyze the competing relationships of different cargo types in different ports within the same region, coordinate the distribution of cargos in the region, and provide new ideas and methods for the study of the impact relationships among ports, meanwhile provide effective basis for the management and development of the port.

\section{The L-V Model with the Multiple Cargo Specie of Multiple Ports}

In a certain area, a port can be seen as a population, and the throughput of the port is similar to the number of population. Populations grow in a certain natural environment and do not suddenly die out or grow explosively in a short period of time. The growth rate is relatively stable. Due to the scarcity of resources, different populations will have different relationships because of their interactions. The quantity will eventually reach the environmental capacity. Homoplastically, the port in a certain area, the throughput mainly depends on the resources of the hinterland. Within a certain period of time, the port supply market is relatively stable and the throughput growth rate is relatively stable. Due to the limited resources of the hinterland, the throughput of the port cannot be unlimitedly increased. At the same time, due to the proximity of geographical location and the similarity of the cargo structure, different ports in the same area may cooperate with each other, win symbiosis with each other, and may also compete viciously and seize limited market resources. Ultimately, the throughput of each port will tend to be stable.

Assume that there is a certain rule between port throughput and limited resources in a certain area where there is no second port participating in competition. Use the Logistics model to describe the changes of port throughput. $X(t)$ denotes the port throughput at time $t$, and $\mathrm{dX}(\mathrm{t}) / \mathrm{dt}$ denotes the throughput growth rate. In

"Corresponding author: 1ei_zhiyi@163.com 
reality, the port throughput cannot grow indefinitely. Assume that $\mathrm{N}$ is the maximum capacity of the market and $r$ represents the natural growth rate of port throughput. The growth of port throughput is in line with the description of the Logistics model and can be expressed as:

$$
\frac{d X(t)}{d t}=r X(t)\left[1-\frac{X(t)}{N}\right]
$$

Assume that there is a second port in the market, the emergence of the second port threatens the monopoly status of the first port, adversely affect the growth of the throughput of the first port, when the two competing ports are in the same market, they will grab limited customer resources and market share with each other, while they may complement each other and promote each other. Considering that there are multiple ports and species competiting and cooperating in the same area, the Lotka-Volterra model is improved to analyze multiple populations. The analysis results are more consistent with the actual situation and have stronger robustness.

Assuming there are $\mathrm{n}$ ports in a certain area, the change in cargo throughput of each port is consistent with the Logistics growth model, and $\mathrm{X}_{\mathrm{i}}(\mathrm{t})$ represents the transaction size of the cargo throughput of the i-th port at time $t,\left(d X_{i}(t)\right) / d t$ represents the growth rate of the cargo throughput transaction at the i-th port. Therefore, the growth process and correlation of the transaction size of multiple port cargo throughputs can be described by the multi-group Lotka-Volterra model:

$$
\frac{d X_{i}(t)}{d i}=X_{i}\left(a_{i 0}+\sum_{j=1}^{n} a_{i j} X_{i} X_{j}\right)
$$

Where i,j $=1,2, \ldots, \mathrm{n}$, ie

$$
\left\{\begin{array}{c}
\frac{d X_{1}}{d t}=a_{10} X_{1}+a_{11} X_{1}^{2}+a_{12} X_{1} X_{2}+\cdots+a_{1 n} X_{1} X_{n} \\
\frac{d X_{2}}{d t}=a_{20} X_{2}+a_{21} X_{2} X_{1}+a_{22} X_{2}^{2}+\cdots+a_{2 n} X_{2} X_{n} \\
\quad \vdots \\
\frac{d X_{n}}{d t}=a_{n 0} X_{n}+a_{n 1} X_{1}^{2}+a_{n 2} X_{n} X_{2}+\cdots+a_{n n} X_{n}^{2}
\end{array}\right.
$$

Among them, $a_{i j}$ indicates the influence of the cargo throughput of the $\mathrm{j}$-th port on the cargo throughput of the i-th port.

When $a_{i j}>0$, port $j$ plays a facilitating role for port $i$; when $\mathrm{a}_{\mathrm{ij}}<0$, port $\mathrm{j}$ plays a role in blocking port $\mathrm{i}$. The positive and negative signs of the parameters $\mathrm{a}_{\mathrm{ij}}$ and $\mathrm{a}_{\mathrm{ji}}$ determine the competition and cooperation between the regional port $i$ and the port $j$. The details are as follows:

When $\mathrm{a}_{\mathrm{ij}}>0$ and $\mathrm{a}_{\mathrm{ji}}>0$, port $\mathrm{i}$ and port $\mathrm{j}$ mutually promote each other, then port $i$ and port $j$ are reciprocal coexistence relations. They have the same interests and are a stable equilibrium. Ultimately, the two sides mutually benefit and win together;

When $\mathrm{a}_{\mathrm{ij}}>0$ and $\mathrm{a}_{\mathrm{ji}}<0$, port $\mathrm{j}$ plays a facilitating role for port $\mathrm{i}$, and port i plays a role in blocking port $\mathrm{j}$, then port $\mathrm{i}$ and port $\mathrm{j}$ are predatory-predatory relationships. Not exactly the same, it is an unstable equilibrium. If you let it go, there may be two consequences. First, excessive competition will develop into vicious competition. Eventually it will lead to a loss of both sides. Second, it will develop into an extreme situation. The port $\mathrm{j}$ will be defeated and exit. In the market, the port $\mathrm{i}$ has become a monopoly and has become a monopoly;

When $\mathrm{a}_{\mathrm{ij}}<0$ and $\mathrm{a}_{\mathrm{ji}}>0$, port $\mathrm{j}$ plays a role in blocking port $\mathrm{i}$, port $\mathrm{i}$ plays a role in promoting port $\mathrm{j}$, and port $\mathrm{i}$ and port $\mathrm{j}$ are predator-predator, mutual interest. Not exactly the same, it is an unstable equilibrium. If you leave it alone, there may be two consequences. First, excessive competition will be formed and vicious competition will be developed. Eventually it will lead to a loss of both sides. Second, it will develop into an extreme situation. The port $\mathrm{j}$ will be defeated and exit. In the market, the port $\mathrm{i}$ has become a monopoly and has become a monopoly;

When $a_{i j}<0$ and $a_{j i}<0$, port $i$ and port $j$ mutually promote each other, then port $i$ and port $j$ are in complete competition, excessive competition, and vicious competition, which ultimately results in two loses.

\section{Different Kinds of Freight of 4 Ports in Fujian Province for Example}

The Fuzhou, Xiamen, Quanzhou and Meizhouwan ports of Fujian Province are taken to analyze, the corresponding four-population Lotka-Volterra model is rewritten as:

$$
\left\{\begin{array}{l}
\frac{d X_{1}}{d t}=a_{10} X_{1}+a_{11} X_{1}^{2}+a_{12} X_{1} X_{2}+a_{13} X_{1} X_{3}+a_{14} X_{1} X_{4} \\
\frac{d X_{2}}{d t}=a_{20} X_{2}+a_{21} X_{2} X_{1}+a_{22} X_{2}^{2}+a_{23} X_{2} X_{3}+a_{24} X_{2} X_{4} \\
\frac{d t}{d t}=a_{30} X_{3}+a_{31} X_{3} X_{1}+a_{32} X_{3} X_{2}+a_{33} X_{3}^{2}+a_{34} X_{3} X_{4} \\
\frac{d t}{d t}=a_{40} X_{4}+a_{41} X_{4} X_{1}+a_{42} X_{4} X_{2}+a_{43} X_{4} X_{3}+a_{44} X_{4}^{2}
\end{array}\right.
$$

In the parameter estimation of the Lotka-Volterra model consisting of four ports, the results of Kloppers and Greeff[12] were used as reference to estimate parameters using linear regression parameters.

\subsection{Data calculation}

The dry bulk throughputs of the 4 ports in Fujian province in 2017 is shown in Table 1, in which FP means Fuzhou Port, XP means Xiamen Port, MP means Meizhouwan Port and QP means Quanzhou Port.And the Dry Bulk Competition Patterns are shown in Table 2.

Table 1. Dry bulk throughputs of 12 months $\left(10^{4} \mathrm{t}\right)$.

\begin{tabular}{|c|c|c|c|c|c|c|}
\hline & Jan. & Feb. & Mar. & Apr. & May. & Jun. \\
\hline FP & 581.79 & 560.39 & 587.72 & 588.62 & 605.49 & 603.94 \\
\hline XP & 563.42 & 632.26 & 616.55 & 623.82 & 628.84 & 624.67 \\
\hline MP & 299.75 & 335.71 & 361.13 & 319.53 & 327.45 & 332.84 \\
\hline QP & 264.47 & 238.03 & 247.5 & 214.91 & 228.45 & 254.73 \\
\hline & Jul. & Aug. & Sep. & Oct. & Nov. & Dec. \\
\hline FP & 574.95 & 705.73 & 680.42 & 810.3 & 737.06 & 685.84 \\
\hline XP & 487.79 & 471.71 & 502.02 & 690.26 & 575.74 & 568.16 \\
\hline MP & 283.42 & 327.73 & 305.4 & 308.15 & 292.01 & 220.66 \\
\hline QP & 266.9 & 223.4 & 253.66 & 227.01 & 201.59 & 287.79 \\
\hline
\end{tabular}


Table 2. Dry Bulk Competition Patterns of 4 Ports in Fujian

\begin{tabular}{|c|c|c|c|c|}
\hline & FP1 & XP2 & MP3 & QP4 \\
\hline FP1 & - & 2 preys on 1 & mutualism & 1 preys on 4 \\
\hline XP2 & 2 preys on 1 & - & 1 preys on 4 & mutualism \\
\hline MP3 & mutualism & 2 preys on 3 & - & $\begin{array}{c}\text { perfect } \\
\text { competition }\end{array}$ \\
\hline QP4 & 1 preys on 4 & mutualism & $\begin{array}{c}\text { perfect } \\
\text { competition }\end{array}$ & - \\
\hline
\end{tabular}

Table 3 and Table 4 show the Container throughputs of the ports in 2017 and the Competition Patterns.

Table 3. Container throughputs of 12 months $\left(10^{4} \mathrm{TEU}\right)$.

\begin{tabular}{|c|c|c|c|c|c|c|}
\hline & Jan. & Feb. & Mar. & Apr. & May. & Jun. \\
\hline FP & 25.28 & 19.95 & 25.06 & 22 & 25.2 & 26.56 \\
\hline XP & 79.65 & 61.75 & 81.81 & 80.81 & 86.17 & 90.96 \\
\hline MP & 0.29 & 0.36 & 0.2 & 0.38 & 0.28 & 0.46 \\
\hline QP & 14.73 & 13.12 & 19.22 & 17.57 & 20.2 & 19.98 \\
\hline & Jul. & Aug. & Sep. & Oct. & Nov. & Dec. \\
\hline FP & 24.59 & 15.77 & 15.06 & 14.69 & 15.43 & 27.49 \\
\hline XP & 94.59 & 69.3 & 70.94 & 69.57 & 64.33 & 89.43 \\
\hline MP & 0.45 & 0.19 & 0.13 & 0.15 & 0.16 & 0.37 \\
\hline QP & 18.87 & 1.11 & 1.12 & 1.2 & 1.09 & 15.28 \\
\hline
\end{tabular}

Table 4. Container Competition Patterns of 4 Ports in Fujian

\begin{tabular}{|c|c|c|c|c|}
\hline & FP1 & XP2 & MP3 & QP4 \\
\hline FP1 & - & mutualism & 1preys on 3 & 1 preys on 4 \\
\hline XP2 & mutualism & - & 2 preys on 3 & $\begin{array}{c}\text { perfect } \\
\text { competition }\end{array}$ \\
\hline MP3 & 1preys on 3 & 2 preys on 3 & - & $\begin{array}{c}\text { perfect } \\
\text { competition }\end{array}$ \\
\hline QP4 & 1 preys on 4 & $\begin{array}{c}\text { perfect } \\
\text { competition }\end{array}$ & $\begin{array}{c}\text { perfect } \\
\text { competition }\end{array}$ & - \\
\hline
\end{tabular}

Table 5 and Table 6 show the liquid bulk throughputs of the ports in 2017 and the Competition Patterns.

Table 5. Liquid bulk throughputs of 12 months $\left(10^{4} \mathrm{t}\right)$.

\begin{tabular}{|c|c|c|c|c|c|c|}
\hline & Jan. & Feb. & Mar. & Apr. & May. & Jun. \\
\hline FP & 22.95 & 20.2 & 19.61 & 16.13 & 16.94 & 25.44 \\
\hline XP & 35.76 & 27.65 & 38.22 & 37.82 & 44.5 & 30.67 \\
\hline MP & 316.46 & 285.67 & 339.53 & 291.82 & 298.16 & 278.34 \\
\hline QP & 21.43 & 14.98 & 16.49 & 13.32 & 18.6 & 16.48 \\
\hline & Jul. & Aug. & Sep. & Oct. & Nov. & Dec. \\
\hline FP & 28.08 & 24.64 & 29.94 & 27.09 & 30.93 & 29.85 \\
\hline XP & 43.43 & 37.38 & 18.21 & 32.71 & 36.83 & 32.19 \\
\hline MP & 310.71 & 298.05 & 330.68 & 276.21 & 331.86 & 211.88 \\
\hline QP & 16.29 & 22.58 & 16.75 & 17.74 & 21.52 & 17.95 \\
\hline
\end{tabular}

Table 6. Liquid Bulk Competition Patterns of 4 Ports in Fujian

\begin{tabular}{|c|c|c|c|c|}
\hline & FP1 & XP2 & MP3 & QP4 \\
\hline FP1 & - & 2 preys on 1 & 3 preys on 1 & mutualism \\
\hline XP2 & 2 preys on 1 & - & 3 preys on 2 & mutualism \\
\hline MP3 & 3 preys on 1 & 3 preys on 2 & - & mutualism \\
\hline
\end{tabular}

\begin{tabular}{|l|l|l|l|l|}
\hline QP4 & mutualism & mutualism & mutualism & - \\
\hline
\end{tabular}

\section{Competition and Cooperation}

According to the "Outline for Accelerating the Development of Ports (2014-2018)" (hereinafter referred to as the "Outline") issued by the Fujian Provincial Government, it is proposed to increase the strength of port construction and strive to create a "two sets of scattered two liquids" core port area. Xiamen Port Haicang and Fuzhou Port of Jiangyin, which mainly consist of container transportation, are mainly dry and bulk cargo transportations. They are Fuzhou Bay, Luoyuan Bay and North Shore of Meizhou Bay. The south shore of Meizhou Bay is dominated by liquid bulk cargo transportation. Xiamen Port Gulei and other core port areas. This paper takes the outline as the goal and analyzes the status quo of the co-opetition of different cargos in four ports of Fujian based on the model results, and puts forward reasonable suggestions.

Container transportation. First, we analyze the Fuzhou Port and Xiamen Port to which the "Two Sets" port area belongs. Based on the data and calculations of the previous analysis, we know that the container transport is mainly in Fuzhou Port and Xiamen Port. The swallow volume of the two ports accounts for $89.06 \%$ of the total in the province. Consistent with the Outline Goals, the relationship between the two is mutualism. The container throughputs of the two ports have relatively high performance, and they should continue to maintain the competitive situation of making progress together and achieving mutual benefit. The throughput of Meizhouwan Port accounts for only $0.25 \%$ of the province, and the throughput of Quanzhou Port accounts for $10.68 \%$ of the province. Under the situation where two heavyweight container ports coexist in sympathy, Meizhouwan Port and Quanzhou Port are preyed on by Fuzhou Port. Xiamen Port preys on Meizhouwan Port. At the same time, the Meizhouwan Port and Quanzhou port are completely competitive. The environment is relatively poor. Access to data is available in 2017. Accumulatively to December, the container routes in the province are shown in Table 7.

Table 7. Routes of 4 ports in Fujian in 2017

\begin{tabular}{|c|c|c|c|c|c|}
\hline & Total & FP & MP & QP & XP \\
\hline Total of province & 270 & 72 & 4 & 59 & 135 \\
\hline $\begin{array}{c}\text { Foreign trade } \\
\text { line }\end{array}$ & 121 & 29 & 0 & 13 & 79 \\
\hline Inner branch line & 36 & 15 & 2 & 4 & 15 \\
\hline Inner trade line & 113 & 28 & 2 & 42 & 41 \\
\hline
\end{tabular}

In contrast, Meizhouwan Port is in its infancy, with a total of four routes, accounting for $1.48 \%$ of the province. Quanzhou Port has a dominant position in domestic trade, with a total of 42 domestic trade lines, accounting for $37.17 \%$ of the province's total. Xiamen Port's domestic trade routes are quite similar, and domestic container transport has dominated the market for a long time. Therefore, Quanzhou Port and Xiamen Port are completely competitive. 
Dry bulk shipping refers to the transportation of coal and products, metal ore and mineral construction materials. According to the Fuzhou Port and Meizhouwan Port to which the "Shuangsan" port belongs, Fuzhou Port accounts for $36.02 \%$ of the total amount of the province, Meizhouwan Port accounts for $17.41 \%$, and the throughput of Meizhou Bay is not the best. However, the two ports are in mutualism and have certain advantages in the competing relationships of the four ports. In this situation, Xiamen Port and Quanzhou Port: Xiamen Port occupies $32.25 \%$ of the total amount of the province. The throughput is far greater than that of Meizhouwan Port and the status is not to be underestimated. Therefore, it's reasonable that Xiamen Port preys on Fuzhou Port and Meizhouwan Port. It shows that Xiamen Port has an advantage in the dry bulk market, and it also has the upper hand in the competing relationship of the four ports. Quanzhou Port is preyed on by Fuzhou Port. Quanzhou Port and Meizhouwan Port are completely competitive, while Quanzhou Port and Xiamen Port are in mutualism. The throughput of Quanzhou Port is the lowest in 4 ports, accounting for only 13.6 percent of the province. $\%$, there is also no advantage in the competing relationship with other ports. It can be seen that Quanzhou Port should clarify the main cargo types and actively create distinctive port areas.

Liquid bulk cargo transportation. The transport of liquid bulk cargoes, ie oil, gas and products, first analyzes the relationship between Meizhouwan Port and Xiamen Port to which the "Liquid" port area belongs. The throughput of Meizhouwan Port and Xiamen Port account for $88.73 \%$ of the province's total. The throughput of Meizhouwan Port is greater than that of Xiamen Port. Meizhouwan Port preys on Xiamen Port . The throughput of Meizhouwan Port is superior both in terms of throughput volume and relationship. The development momentum of Meizhouwan Port is better than that of Xiamen Port. Xiamen Port should be properly adjusted to rectify the situation in a timely manner. In this situation, the remaining Fuzhou Port and Quanzhou Port are analyzed: Fuzhou Port is preyed on by Xiamen Port and Meizhouwan Port. Quanzhou Port and the other three ports are mutually beneficial. The throughputs of Fuzhou Port and Quanzhou Port arecomparable.In the competition and cooperation relationship of the four ports, Quanzhou Port is generally better than Fuzhou Port, and Fuzhou Port should actively strengthen cooperation with other ports.

\section{Suggests}

A single port should clearly define its own development orientation and core business, enhance its core competitiveness, base itself on the main business of each port, complement each other's advantages, and be open to reciprocity, so as to enhance the brand benefits of the port group and significantly reduce the cost of the port.

Fuzhou Port should cooperate with Xiamen Port, Meizhou Bay Port and Quanzhou Port respectively in containers, dry bulk cargo and liquid bulk cargo business.
Xiamen Port should continue to strengthen cooperation with Fuzhou Port to achieve a win-win situation in containers business, and strengthen the construction of dry bulk port areas and form a "three pillars" situation with Fuzhou Port and Meizhouwan Port. For liquid bulk cargo, it is necessary to strengthen the construction of liquid bulk shipping port areas and increase the competitiveness.

Quanzhou Port should focus on the development of domestic trade container transportation, consolidate the status of the coastal domestic trade container, and strengthen cooperation with Quanzhou Port, and strengthen cooperation with Xiamen Port to improve the competitiveness in dry bulk business. And the existing relationships should be maintained and more in-depth to achieve steady growth in liquid bulk business.

Meizhouwan Port should gradually expand foreign trade routes and create regional modern trade logistics centres to achieve dislocation development and avoid vicious competition. And continue to strengthen cooperation with Fuzhou Port in dry bulk business to strengthen the anti-risk capabilities. Meizhouwan Port has the highest throughput and is also in an advantageous position in the competing relationship with other ports that should be continued.

\section{References}

1. Lotka A J. Elements of Physical Biology. American Journal of Public Health, 15(9), 812(1925).

2. Volterra V. Variazioni E Fluttuazioni Del Numero Dindividui in Specie Animali Conviventi. Mem Acad Lincei Roma 2, 31-113(1926)

3. Vladimir Balaz, Allan M. Williams. Diffusion and competition of voice communication technologies in the Czech and Slovak Republics, 1948-2009. Technological Forecasting and Social Change 2, 393-404(2012)

4. Qiu-sheng TANG, WangYong, Hua-dong NIE. Foreast on the competition relationship between medes of transportation based on "Gray L-V" model. Highway Engineering, 42(1):96-100 (2017)

5. Bing SUN, Hong-tao YAO. Study on competition mechanism of core-structure innovation network under the circumstance of globalization-a simulation study based on LV-EG Model. Operations Research and Management Science, 25(1):192-202 (2016)

6. Wei QIU. Jinye LI .Research on the interaction relationship between resource-based industries and non-resource-based industries: a case study of Xinjiang. Journal of Xinjiang University, Natural Science Edition, 35(1), 22-29(2018)

7. Lu YU. Analyze on the evolution of china's port industry based on gynaecology . Ocean University of China, (2010)

8. Zhi-xiang ZHOU. Study on the coopetition relationship between container ports based on the Lotka-Volterra model. Chang'an University, (2015) 
9. Kloppers P H, Greeff J C. Lotka-Volterra Model

Parameter Estimation using Experiential Data.

Applied Mathematics and Computation, 224,817-

825 (2013) 